\title{
Distribution and diversity of mycoplasma plasmids: lessons from cryptic genetic elements
}

\author{
Marc Breton ${ }^{1,2 \dagger}$, Florence Tardy ${ }^{3 \dagger}$, Emilie Dordet-Frisoni ${ }^{4,5}$, Eveline Sagne ${ }^{4,5}$, Virginie Mick ${ }^{3}$, Joël Renaudin ${ }^{1,2}$, \\ Pascal Sirand-Pugnet ${ }^{1,2}$, Christine Citti ${ }^{4,5}$ and Alain Blanchard ${ }^{1,2,6^{*}}$
}

\begin{abstract}
Background: The evolution of mycoplasmas from a common ancestor with Firmicutes has been characterized not only by genome down-sizing but also by horizontal gene transfer between mycoplasma species sharing a common host. The mechanisms of these gene transfers remain unclear because our knowledge of the mycoplasma mobile genetic elements is limited. In particular, only a few plasmids have been described within the Mycoplasma genus.

Results: We have shown that several species of ruminant mycoplasmas carry plasmids that are members of a large family of elements and replicate via a rolling-circle mechanism. All plasmids were isolated from species that either belonged or were closely related to the Mycoplasma mycoides cluster; none was from the Mycoplasma bovis-Mycoplasma agalactiae group. Twenty one plasmids were completely sequenced, named and compared with each other and with the five mycoplasma plasmids previously reported. All plasmids share similar size and genetic organization, and present a mosaic structure. A peculiar case is that of the plasmid pMyBK1 from M. yeatsii; it is larger in size and is predicted to be mobilizable. Its origin of replication and replication protein were identified. In addition, pMyBK1 derivatives were shown to replicate in various species of the M. mycoides cluster, and therefore hold considerable promise for developing gene vectors. The phylogenetic analysis of these plasmids confirms the uniqueness of pMyBK1 and indicates that the other mycoplasma plasmids cluster together, apart from the related replicons found in phytoplasmas and in species of the clade Firmicutes.
\end{abstract}

Conclusions: Our results unraveled a totally new picture of mycoplasma plasmids. Although they probably play a limited role in the gene exchanges that participate in mycoplasma evolution, they are abundant in some species. Evidence for the occurrence of frequent genetic recombination strongly suggests they are transmitted between species sharing a common host or niche.

Keywords: Mycoplasma,Plasmid,Replication,Rep protein,Gene transfer,Evolution,Expression vector,Mycoplasma mycoides,Mycoplasma capricolum,Mycoplasma yeatsii

\section{Background}

Horizontal gene transfer (HGT) is recognized as the major force in bacterial genome evolution (for review see: [1]). It has contributed to the diversity of bacterial species and to the success of bacterial colonization of almost all the possible niches on earth. HGT events have been detected in most bacteria for which genome

\footnotetext{
* Correspondence: ablancha@bordeaux.inra.fr

${ }^{\dagger}$ Equal contributors

'University Bordeaux, UMR 1332 Biologie du Fruit et Pathologie, 71 avenue Edouard Bourlaux, F-33140, Villenave d'Ornon, France

${ }^{2}$ INRA, UMR 1332 Biologie du Fruit et Pathologie, 71, avenue Edouard

Bourlaux, F-33140, Villenave d'Ornon, France

Full list of author information is available at the end of the article
}

sequences are available. Yet many questions remain about the dynamics of gene exchange and the mechanisms underlying these DNA transfers. Some bacterial species seem particularly well equipped for sharing DNA at high frequency (for review see: [2]). These bacteria present an abundance of different mobile genetic elements (MGE) and have other characteristics such as natural competence, efficient machinery for homologous recombination and numerous secretion systems that favor gene exchange. For other bacteria with limited MGE repertoire and routes of DNA transfer, the means of genetic exchange are not so obvious.

The class Mollicutes is a group of wall-less bacteria that colonize a variety of hosts, from plants to humans, and

\section{Biomed Central}


are characterized by a small genome with a low $\mathrm{G}+\mathrm{C}$ content $[3,4]$. Mollicutes are thought to have evolved from a common ancestor with Firmicutes through successive genome losses [5]. This drastic evolution resulted in some mollicutes, such as Mycoplasma genitalium, having a cell with a highly reduced genome that is considered the best representative of a natural minimal cell [6]. However, genome down-sizing was not the sole force operating during evolution because it has been shown that mollicutes were also able to exchange genetic material through HGT. Indeed, comparative genomics of ruminant mycoplasmas predicted that up to $18 \%$ of the Mycoplasma agalactiae genome has undergone HGT with mycoplasmas of the distinct Mycoplasma mycoides cluster [4]. A smaller amount of HGT has also been detected between two bird pathogens M. gallisepticum and M. synoviae, and between two human urogenital pathogens, M. hominis and Ureaplasma parvum $[7,8]$. Obviously, sharing a common host was a requisite for HGT but the underlying mechanisms behind these HGT events have yet to be described. A number of MGE, including integrative and conjugative elements (ICEs), insertion sequences (IS), phages and plasmids, have been described in these bacteria and are potential candidates for mediating these genetic transfers.

Although usually abundant in species belonging to the phylum Firmicutes, only a few plasmids have been described in the different genera of the Mollicutes (Figure 1). They were first detected in the genus Spiroplasma $[11,12]$ and later proved widely distributed in this genus [13]. Spiroplasma plasmids that have a size ranging from 5 to more than $30 \mathrm{kbp}$ were initially termed cryptic as no specific phenotype was associated

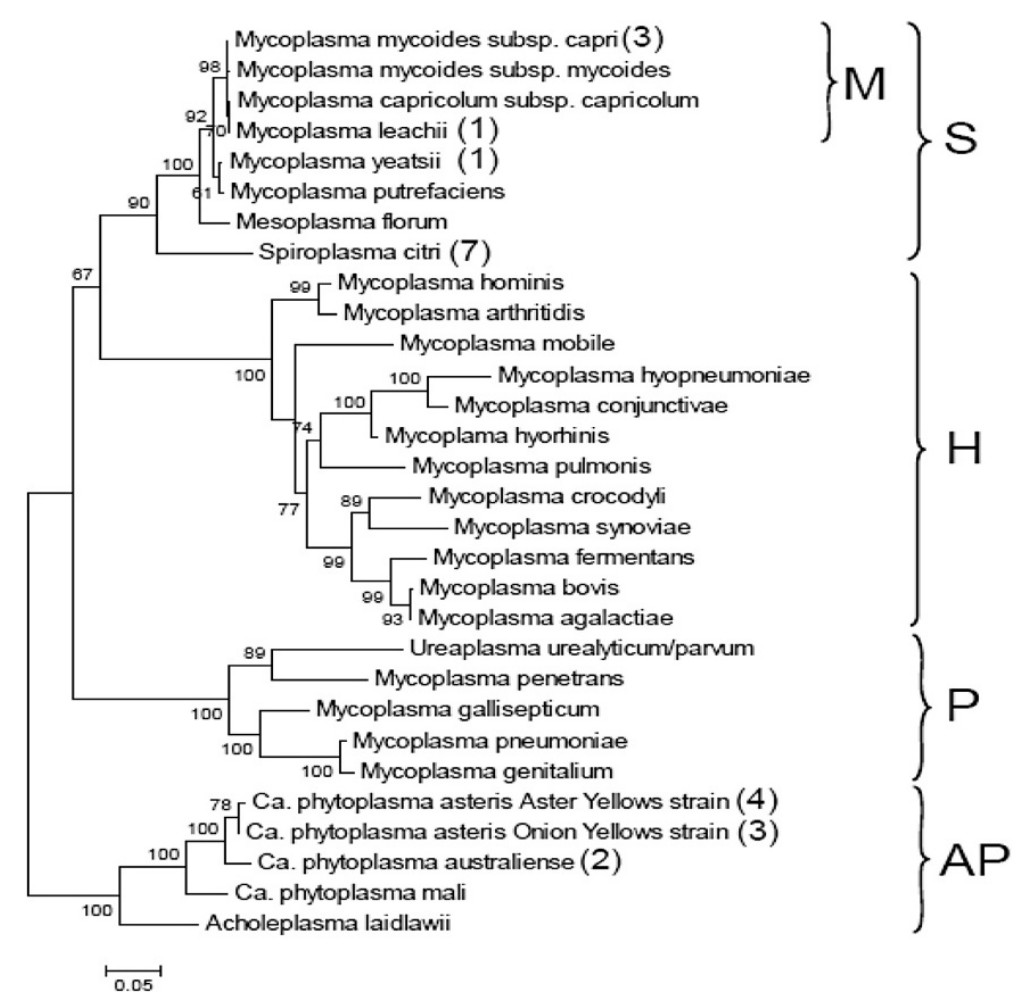

Figure 1 Mollicute phylogenetic tree including species for which at least one genome sequence is available. The mollicute evolutionary history was inferred by using the Maximum Likelihood method based on the Tamura-Nei model [9]. The tree with the highest log likelihood (-8994.2924) is shown. The percentage of trees in which the associated taxa clustered together is shown next to the branches. Initial tree(s) for the heuristic search were obtained automatically as follows. When the number of common sites was $<100$ or less than one fourth of the total number of sites, the maximum parsimony method was used; otherwise BIONJ method with MCL distance matrix was used. A discrete Gamma distribution was used to model evolutionary rate differences among sites ( 5 categories $(+G$, parameter $=0.5355)$ ). The tree is drawn to scale, with branch lengths measured in the number of substitutions per site. Nucleotide sequences (16S rDNA) from 30 species were aligned. After removing all positions containing gaps and missing data, the final dataset included 1136 positions.Evolutionary analyses were conducted in MEGA5 [10]. The number in parentheses indicates the number of plasmids previously described for each species. No indication means that there is no reported evidence of plasmid in these species. For M. mycoides subsp. capri, each one of the three plasmids was identified in a different strain. The letters on the right side of the figure indicate the phylogenetic groups within the Mollicutes: S, Spiroplasma; H: Hominis; P: Pneumoniae; AP: Acholeplasma-Phytoplasma; M: Mycoplasma mycoides cluster. 
with their presence. However, some of these plasmids carry genetic determinants that play a role in the transmission of the Spiroplasma citri by its vector insect [14,15]. Within Mollicutes, the other phytopathogen organisms are phytoplasmas that remain yet uncultivated. In several Candidatus phytoplasma species, plasmids with a size range from 2.6 to $10.8 \mathrm{kbp}$ have also been described (for a review see [16]). Unlike the spiroplasma plasmids for which no homology was detected in databases, all the phytoplasma plasmids encode a replication protein sharing similarities with the Rep proteins involved in rolling-circle replication (RCR) $[17,18]$. For the genus Mycoplasma, which includes over 100 species, among which are significant pathogens of animals and humans [19], only five plasmid sequences are available in databases [20-23] (Figure 1). All 5 plasmids have been isolated in Mycoplasma species belonging to the Spiroplasma phylogenetic group but are not related to the ones described in Spiroplasma species. Four are from closely related species of the $M$. mycoides cluster and three of them (pADB201, pKMK1, and pMmc-95010) are from the same sub-species, $M$. mycoides subsp. capri $(\mathrm{Mmc})$. In contrast to the apparent scarcity of mycoplasma plasmids, other investigators have reported a much higher prevalence of strains with plasmids but these data were only based on agarose gel detection of extrachromosomal DNA, without DNA sequencing [24].

The present work was conducted in order to better comprehend the nature and extend of the plasmid repertoire of two main groups of ruminant mycoplasmas: the $M$. agalactiae- $M$. bovis group and the species found within or close to the M. mycoides cluster, two phylogenetically distant groups between which a high level of HGT has been predicted in silico [4] (Figure 1). Several plasmids were isolated from various species and completely sequenced. Comparative analyses indicated that, except for the recently described pMyBK1 from $M$. yeatsii [25], all plasmids belong to the same large family of rolling-circle replicons found in Firmicutes. Plasmid pMYBK1 represents a new family of replicons that can be transformed and maintained in other mycoplasma species. The study further indicates that plasmids can be commonly found in several Mycoplasma species colonizing ruminants and therefore, could contribute to the genetic transfers that have been revealed by comparative genomics.

\section{Methods}

\section{Mycoplasma strains, growth conditions and DNA} purification

All mycoplasma strains used in this study (Table 1) are kept in the collection maintained by the Anses laboratory of Lyon and most of them were isolated as part of the activities of the Vigimyc network [26]. They were cultivated at $37^{\circ} \mathrm{C}$ in Mycoplasma broth base supplemented as for SP4 medium [27]. Mycoplasma transformants were sub-cultured in modified Hayflick broth [28] supplemented with $0.4 \%(\mathrm{w} / \mathrm{v})$ pyruvate, $0.2 \%(\mathrm{w} / \mathrm{v})$ glucose and 5-15 $\mu \mathrm{g}$ of tetracycline $\mathrm{mL}^{-1}$. Spiroplasma citri was grown at $32^{\circ} \mathrm{C}$ in SP4 broth withoutfresh yeast extract. Escherichia coli DH10B was used as the host strain in cloning experiments and was grown in LB medium supplemented with $100 \mu \mathrm{g} \cdot \mathrm{ml}^{-1}$ of ampicillin for selection.

Mycoplasma and spiroplasma genomic DNA were prepared using the Wizard Genomic DNA Purification kit (Promega) or by standard phenol/chloroform procedures. Plasmid DNA was purified using either the Wizard SV Minipreps DNA purification kit (Promega) or QIAprep Spin Miniprep Kit (Qiagen) with the low-copy plasmid protocol. When several plasmids were present, as in $M$. yeatsii GIH TS, the individual bands visualized on agarose gel were purified following an agarase $\left(\operatorname{AgarACE}^{\mathrm{TM}}\right.$, Promega) treatment.

\section{Screening mycoplasma strains for the presence of plasmids}

The presence of plasmid was screened by agarose gel electrophoresis of $1 \mu \mathrm{g}$ of genomic DNA extracted from cells collected from stationary phase cultures.

\section{Determination of plasmid copy number}

The copy number of pMyBK1 and pMG2B-1 was estimated by gel assay as previously described [29] except that lysozyme treatment was omitted. Serial twofold dilutions of the genomic DNA extracted from a logarithmic phase culture of $M$. yeatsii $\mathrm{GIH}^{\mathrm{T}}$ were analyzed by $0.8 \%(\mathrm{w} / \mathrm{v})$ agarose gel electrophoresis. After ethidium bromide staining, the relative intensities of individual bands, both plasmid and chromosome, were quantified using the ImageJ software [30]. The copy numbers of pMyBK1 and pMG2B1 were derived from the intensity of each band taking into account their respective sizes. The plasmid copy number was also quantified by real-time PCR as reported earlier by others [31]. Amplification and detection were carried out using a Roche LightCycler 480 (Roche Diagnostics) using a SYBR green/fluorescein mix (Applied Biosystem). The glycerol kinase gene glpk was chosen as the reference gene, because it is a conserved single-copy gene that is chromosomally encoded. Fragments of chromosomal glpk (123 bp), pMyBK1 cdsB (90 bp) and pMG2B-1 rep (87 bp) were amplified with primers glpkF/R, cdsBF/R and pMG2B-1F/ $\mathrm{R}$, respectively (Additional file 1: Table S1). The amplification efficiencies were determined through serial tenfold dilutions of the DNA samples using the LightCycler 480 software and were shown to be similar for each target gene, namely $g l p k, c d s B$ and rep. The relative copy number $\mathrm{N}$ of pMyBK1 or pMG2B-1 plasmids was calculated by the 
Table 1 Mycoplasma plasmids analyzed in this study

\begin{tabular}{|c|c|c|c|c|c|}
\hline Taxon & Strain name & Plasmid name & Reference & GenBank access $n^{\circ}$ & Plasmid size \\
\hline \multirow[t]{2}{*}{ M. leachii } & $99 / 0361$ & $\mathrm{pBG7AU}$ & Djordjevik et al. 2001 & AF257325 & $1022 \mathrm{bp}$ \\
\hline & CIRAD063*+ & $\mathrm{pBG7AU}$ & this work & / & $1022 \mathrm{bp}$ \\
\hline \multirow[t]{7}{*}{$M m c$} & GM12 & pKMK1 & King \& Dybvig, 1992 & M81470 & $1875 \mathrm{bp}$ \\
\hline & GC1176-2 & pADB201 & Bergemann et al. 1989 & M25059 & $1717 \mathrm{bp}$ \\
\hline & 95010 & pMmc-95010 & Thiaucourt et al. 2011 & FQ790215 & $1840 \mathrm{bp}$ \\
\hline & 13071 & pMmc-95010-3 & this work & $\rho^{a}$ & 1839 bp \\
\hline & 14227 & pMG1A-1 & this work & JX294729 & $1865 \mathrm{bp}$ \\
\hline & L & pMmc-95010-2 & this work & / & 1802 bp \\
\hline & 4343 & pMG1C-1 & this work & $J \times 294730$ & $1770 \mathrm{bp}$ \\
\hline \multirow[t]{4}{*}{ M. yeatsii } & GIH (TS) & pMyBK1 & Kent et al. 2012 & EU429323 & $3432 \mathrm{bp}$ \\
\hline & GIH (TS) & pMG2B-1 & this work & JX294731 & $1573 \mathrm{bp}$ \\
\hline & 11181 & $\mathrm{pMG} 2 \mathrm{~F}-1$ & this work & $J \times 294732$ & $1656 \mathrm{bp}$ \\
\hline & 15000 & $\mathrm{pMG} 2 \mathrm{~F}-2$ & this work & / & $1652 \mathrm{bp}$ \\
\hline \multirow[t]{2}{*}{ M. cottewii } & VIS (TS) & pMG2C-1 & this work & JX294733 & $1565 \mathrm{bp}$ \\
\hline & 15104 & $\mathrm{pMG} 2 \mathrm{E}-1$ & this work & JX294734 & 1041 bp \\
\hline \multirow[t]{11}{*}{ Mcc } & 14425 & pMG1B-1 & this work & JX294737 & 1732bp \\
\hline & 14667 & pMG1B-2 & this work & / & $1731 \mathrm{bp}$ \\
\hline & 15301 & pMG1B-3 & this work & / & $1731 \mathrm{bp}$ \\
\hline & 5145 & pMG1B-4 & this work & / & $1733 \mathrm{bp}$ \\
\hline & 15250 & pMG1B-5 & this work & / & 1732 bp \\
\hline & 15216 & pMG1B-6 & this work & I & $1734 \mathrm{bp}$ \\
\hline & 14250 & pMG2A-1 & this work & JX294735 & $1573 \mathrm{bp}$ \\
\hline & 11186 & pMG2D-1 & this work & JX294736 & 1722 bp \\
\hline & 14141 & pMG2D-2 & this work & / & $1720 \mathrm{bp}$ \\
\hline & 14332 & pMG2D-3 & this work & I & $1718 \mathrm{bp}$ \\
\hline & 4142 & pMG2D-4 & this work & / & 1720 bp \\
\hline
\end{tabular}

${ }^{a}$ the sequences for which the plasmid is the representative of a series have been deposited in GenBank.

following formula: $\mathrm{N}$ relative $=(1+\mathrm{E})-\Delta \mathrm{Ct}$, where $\mathrm{E}$ and $\Delta C t$ represent the PCR amplification efficiency and the difference between the cycle threshold number $(\mathrm{Ct})$ of $g l p k$ and $c d s B$ or rep reaction, respectively. The experiment was performed in triplicate.

\section{DNA sequencing and sequence analyses}

Purified mycoplasma plasmids were linearized using a restriction enzyme (EcoRI, EcoRV or HindIII) and were then sub-cloned into the pBluescript vector linearized with the same enzyme. The resulting plasmids were sequenced using $\mathrm{T} 7$ and $\mathrm{T} 3$ universal primers or by primer-walking when necessary. When there was not a unique restriction site within the plasmid, multiple restriction fragments were individually sub-cloned and sequenced. The nucleotide sequences were determined by means of at least two overlapping reads on each strand of the whole plasmids. When necessary, complementary plasmid sequences were obtained by direct sequencing of PCR products (for the list of PCR primers see Additional file 1: Table S1). The plasmid sequences determined in this study have been deposited in the GenBank database under the following accession numbers: JX294729 for pMG1A-1, JX294730 for pMG1C-1, JX294731 for pMG2B-1, JX294732 for pMG2F-1, JX294733 for pMG2C-1, JX294734 for pMG2E-1, JX294735 for pMG2A-1, JX294736 for pMG2D-1 and JX294737 for pMG1B-1 (Table 1).

Coding sequences (CDSs) were searched using the AMIGene software ([32], http://www.genoscope.cns.fr/agc/ tools/amigene/). Database searches and comparisons of DNA sequences or DNA-derived protein sequences were carried out using BLAST programs (http://www.ncbi.nlm. nih.gov/blast/). Conserved domains were detected by CDSearch against the CDD resource from NCBI [33]. Protein secondary structures were predicted from sequences using the SOPM method [34]. DNA repeats were identified using the software RepFind [35], nucleic acid folding and calculation of free energy for hairpin formation were determined using the Mfold program [36]. Multiple sequence 
alignments were performed with T-Coffee [37] or ClustalW2 softwares [38]. Subsequent phylogenetic analyses were performed with the Mega 5 software [10] using the neighbor-joining or the maximum likelihood method. Multiple-way pairwise comparisons of plasmid nucleic sequences were conducted with the Artemis Comparison Tool, ACT [39].

\section{Southern blot hybridization and immunoblotting}

The detection of ssDNA intermediates was performed by Southern blot hybridization and S1 nuclease treatment as described previously by others [40]. Total M. yeatsii GIH TS genomic DNA, treated or not with S1 nuclease (10 U/ $\mu \mathrm{g}$ of DNA for $15 \mathrm{~min}$ at room temperature) was electrophoresed using a $0.8 \%$ agarose gel and transferred without prior denaturation to a nylon membrane (Nytran SuPerCharge) by vacuum blotting in 10X SSC buffer (Vacuum Blotter; MP Biomedicals). The air-dried membrane was then UV cross-linked before hybridization with the pMyBK1 [digoxigenin]dUTP-labelled probe using standard stringency conditions. Hybridization signals were detected with anti-digoxigenin-alkaline phosphatase conjugate and CDP-Star as the substrate, according to the manufacturer's instructions (Roche Applied Science). The pMyBK1 probe was generated by PCR amplification with primer pair pMyBK1-F1/R2 (Additional file 1: Table S1).

For protein immunobloting, $10^{7}-10^{8}$ c.f.u. from $M$. yeatsii and $M$. capricolum subsp. capricolum (Mcc) lateexponential-phase cultures were spotted under vacuum onto a nitrocellulose membrane. Immunoblotting was carried out as described previously [41] except that the binding of spiralin-antibodies was visualized by using a goat anti-rabbit immunoglobulin G-peroxidase conjugate and the Super Signal West Pico chemoluminescent substrate (Pierce).

\section{Plasmid constructs and transformation experiments}

Several derivatives of pMyBK1 (pCM-H, pCM-P, pCM-C, pCM-K1-5) were constructed by inserting BglII-digested amplification products from pMyBK1 (BglII site in the primer sequences) into BglII-linearized pSRT2 [42]. Primers used for amplification of fragments from pMyBK1 are listed in Additional file 1: Table S1. In each construct (see Results section and Figure 2), the CDSs of pMyBK1 were kept in the same orientation as that of the pSRT2 tetM gene. To produce $\mathrm{pCM}-\mathrm{K} 3$-spi, the spiralin gene and its promoter were amplified from S. citri GII3 genomic DNA with primer pair SpiERI-F/R, prior to restriction with $E c o R I$ and ligation into EcoRI-linearized pCM-K3. In $\mathrm{pCM}-\mathrm{K} 1 \Delta \mathrm{B}$, the CDSB of $\mathrm{pCM}-\mathrm{K} 1$ was disrupted by a 4-bp insertion creating a unique $\mathrm{XhoI}$ site. To introduce the 4-bp frameshift mutation, the amplification product of pCM-K1 using DeltacdsB-F/DeltacdsB- $\mathrm{R}$ primers was restricted by $\mathrm{XhoI}$ before circularization by self-ligation.
Electrotransformation of $S$. citri was carried out as previously described [43] with 1-5 $\mu \mathrm{g}$ of DNA. Polyethylene glycol-mediated transformation of mycoplasmas was performed as described previously [44] with 5-10 $\mu \mathrm{g}$ of plasmid and transformants were selected by plating on medium containing 5-15 $\mu \mathrm{g} \cdot \mathrm{ml}^{-1}$ of tetracycline.

\section{Results and discussion}

Detection and initial characterization of plasmids from ruminant mycoplasmas

A total of 194 ruminant mycoplasma strains were selected from our collection on the basis that there was no apparent epidemiological link between them. Their distribution amongst taxa is summarized in Table 2. No plasmid was detected in species belonging to the Hominis phylogenetic group, i.e. in the $M$. bovis and $M$. agalactiae species. In contrast, several plasmids were detected in strains belonging to the $M$. mycoides cluster or to closely related species of the Spiroplasma phylogenetic group (Table 2). Indeed, 37 out of the 112 strains screened (33\%) were found to carry plasmids. Although plasmids have already been described for strains belonging to the $M m c, M$. yeatsii and $M$. leachii species, this is the first report of plasmids in M. cottewii and Mcc. While nearly all strains carried a single plasmid, the $M$. yeatsii $(\mathrm{GIH})$ type strain contained two plasmids. Except for the larger plasmid of $M$. yeatsii GIH TS (3.4 kbp), all other plasmids had apparent sizes of 1.0 to $2.0 \mathrm{kbp}$. Also, no correlation between the presence of plasmid and the history of the strains such as the year and/or place of isolation, and the host species (bovine versus caprine), could be established (Additional file 2: Table S2).

Twenty one plasmids, at least one per taxon, were randomly chosen and fully sequenced. Plasmid sizes ranged from 1,041 bp to $1,865 \mathrm{bp}$. To assess the diversity and genetic variability of mycoplasma plasmids, the 21 sequences were compared to each other and to those of the five mycoplasma plasmids available in GenBank: pADB201, pKMK1, and pMmc95010 from $M m c$, pBG7AU from $M$. leachii, and $\mathrm{pMyBK} 1$ from $M$. yeatsii (Table 1). The overall nucleotide identity was calculated after a global alignment for each plasmid-pair. Within individual taxa, pairwise nucleotide identities varied from $100 \%$ to less than $40 \%$ (Additional file 3: Table S3). Indeed, the sequence of the plasmid that we isolated from a $M$. leachii strain was found to be identical to that of the previously described pBG7AU. This result is not surprising since the $2 \mathrm{M}$. leachii strains, though distinct, were recovered from the same outbreak in Australia [21]. Similarly, the 2 field strains of $M$. yeatsii were shown to harbor plasmids that are $97 \%$ identical. In this case, however, the strains sharing the same geographical origin were isolated 8 years apart. In contrast, the 2 plasmids isolated from the $M$. cottewii species were shown to have different sizes (1,565 vs 1,041 bp) and nucleotide 

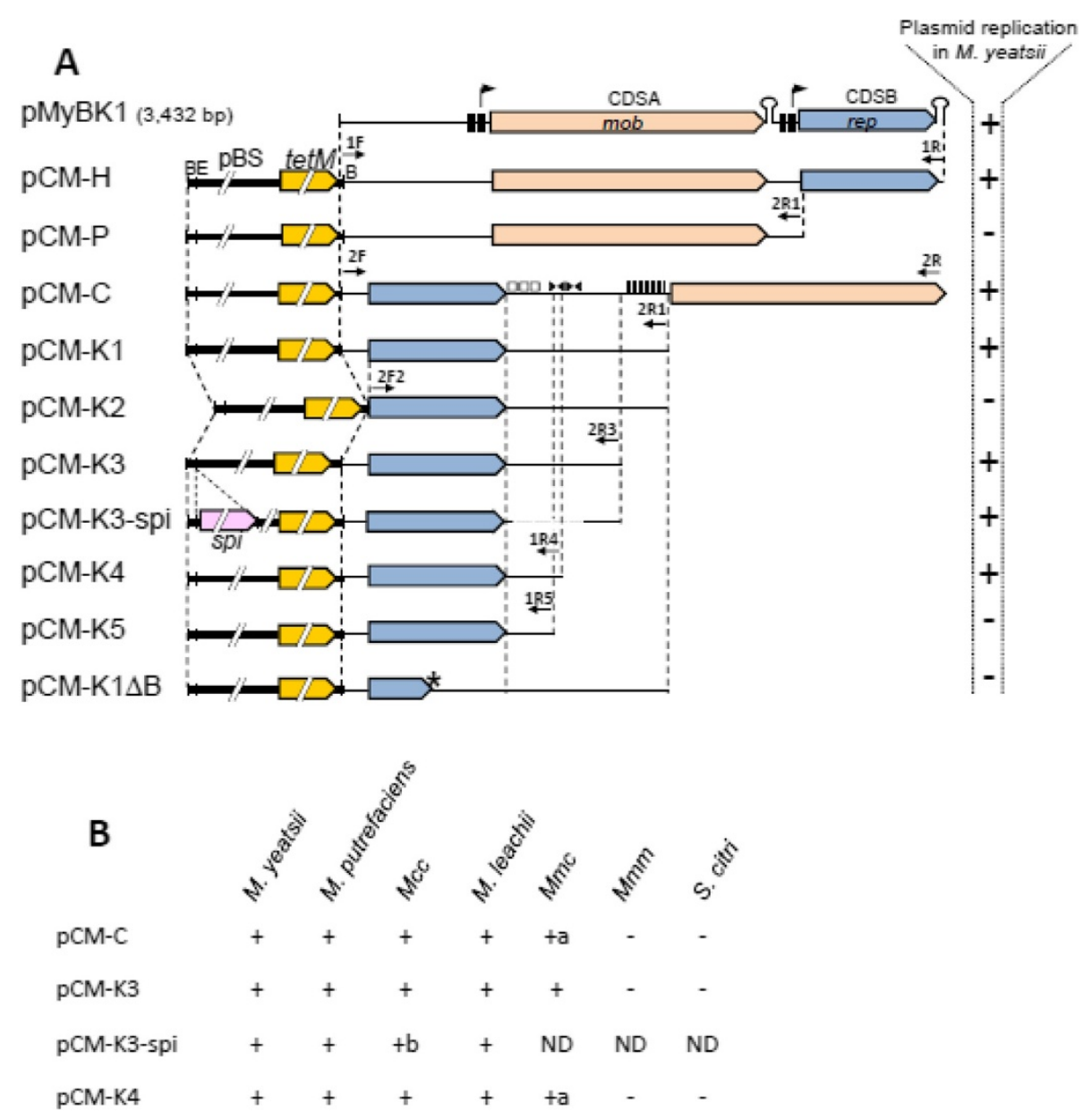

Figure 2 Structural organization and replication ability of pMyBK1 and derivatives. A. Plasmid constructs are described in Methods. Putative promoter and terminator of CDSA and CDSB are indicated for pMyBK1 only. Direct repeats $(\square)$, inverted repeats $(\boldsymbol{\bullet})$ and the GC-rich region (I\|I|) are indicated only for the PCM-C derivative. B, Bglll; E, EcoRl; spi, Spiroplasma citri spiralin gene; tetM, tetracycline resistance gene from transposon $\operatorname{Tn} 916, \mathrm{pBS}$, plasmid pBluescript. The signs on the right indicate the ability (+) and inability (-) to replicate in Mycoplasma yeatsii type strain GIH TS. * indicates a frameshift mutation in the $c d s B$ sequence of $\mathrm{pCM}-\mathrm{K} 1 \Delta \mathrm{B}$. B. The replication ability of 4 pMyBK1 derivatives was evaluated in mollicute species belonging to the Spiroplasma phylogenetic group and shown to be initially plasmid-free: $M$. yeatsii \#13156, $M$. putrefaciens KS1 TS, M. leachii PG50 TS, Mcc California kid TS, Mmc GM12, Mmm T1/44 and S. citri Gll3. The signs on the right indicate the ability $(+)$ and inability $(-)$ to replicate in a given species. ND: not determined. A: plasmid integration in the Mmc chromosome. B: spiralin expression in Mcc was detected by immunoblot.

sequences (42\% identity only). The pMyBK1 plasmid, sequenced by others (Genbank accession \# EU429323; [25]) and also found in the M. yeatsii type strain, is certainly a particular case because of its larger size $(3,422 \mathrm{bp})$ and low nucleotide identity (20-37\%) in comparison to other mycoplasma plasmids.

\section{Proposed nomenclature for mycoplasma plasmids}

With the description of this fairly large set of plasmids, a proposal for a new nomenclature of mycoplasma plasmids seemed justified. First, we considered that there was no need to give a different name to a plasmid that was found identical to a previously described replicon (e.g. pBG7AU). For the plasmids that are very close to each other (nucleotide identity > 95\%), we considered that they were variants and should be given the same name followed by the suffix "-n" where $n$ indicated the number by chronological order in this series of plasmids (Table 1); the plasmid with the suffix "-1" being the prototype of the plasmid series (e.g. pMG1A-1). This same rule was used for variants of plasmids described by others (e.g. pMmc-95010-2). Finally, the plasmids were separated into two groups (G1 and G2) according to their rep sequences (see below). According to this 
Table 2 Detection of plasmids from ruminant

\begin{tabular}{|c|c|c|c|}
\hline $\begin{array}{l}\text { Phylogenetic } \\
\text { group }\end{array}$ & Taxon & $\begin{array}{l}\text { nb of screened } \\
\text { strains }{ }^{\mathrm{a}}\end{array}$ & $\begin{array}{l}\text { strains with } \\
\text { plasmid }^{\mathbf{b}}\end{array}$ \\
\hline \multirow[t]{3}{*}{ Hominis } & M. agalactiae & 40 & 0 \\
\hline & M. bovis & 42 & 0 \\
\hline & Subtotal & 82 & 0 \\
\hline \multirow[t]{7}{*}{ Spiroplasma } & $\begin{array}{l}\text { M. mycoides } \\
\text { subsp. capri }\end{array}$ & 43 & 12 \\
\hline & $\begin{array}{l}\text { M. capricolum } \\
\text { subsp. capricolum }\end{array}$ & 41 & 15 \\
\hline & M. leachii & 10 & 1 \\
\hline & M. yeatsii & 16 & 7 \\
\hline & M. cottewii & 2 & 2 \\
\hline & Subtotal & 112 & 37 \\
\hline & Total & 194 & 37 \\
\hline
\end{tabular}

(a) including the species type strain.

(b) as visualized on agarose gel after total DNA extraction by phenol/ chloroform.

nomenclature, we identified 9 new plasmids (pMG1A-1, pMG1B-1, pMG1C-1, pMG2A-1, pMG2B-1, pMG2C-1, pMG2D-1, pMG2E-1 and pMG2F-1) and 11 variants of these plasmids or of plasmids previously reported. Sequences of these 9 new plasmids have been deposited in GenBank (Table 1).

\section{Mycoplasma plasmids share a common genetic organization}

With the exception of pMyBK1for which a specific analysis is provided further, all plasmids shared the same overall genetic organization, similar to those of $\mathrm{pMmc}$ 95010 [23] and pMV158, a small, broad-host-range plasmid, originally isolated from Streptococcus agalactiae that is considered the prototype of the rolling circle replicating plasmid family [45] (Figure 3A). It consists of two CDSs transcribed in the same direction, followed by an inverted repeat sequence ended by a stretch of thymidine residues that is typical of rho-independent transcription terminators (Tcr; Figure 3A).

The first CDS encodes a 43-53 aa polypeptide predicted to be the transcriptional regulator CopG by homology to that of pMV158 (Figure 3C). Despite the low similarity level between the predicted polypeptides, the key aminoacids within a predicted helix-turn-helix structure are conserved (Figure 3C). In pMV158, the CopG protein regulates the plasmid copy number through the control of cop-rep mRNA synthesis. Furthermore, the copy number of pMV158 is also controlled through a small countertranscribed RNA (ctRNA) [47]. In agreement with this type of regulation, the corresponding transcription signals (promoter Pct and rho independent terminator Tct; Figure $4 \mathrm{~A}$ ) were predicted on the complementary strand in between the two CDS of the various plasmids (Additional file 4: Figure S1).

The second CDS encodes a 196-225 aa polypeptide that was annotated as the replication protein, Rep in pADB201, again by homology to pMV158. All predicted Rep proteins shared a Rep2 domain (Plasmid replication protein, pfam01719). These Rep proteins are known to function as topoisomerases that nick the positive strand at the leading strand origin of replication (dso) during rolling-circle replication [48]. Multiple sequence alignments revealed that the Rep proteins of mycoplasma plasmids shared five conserved motifs (I to V) initially described in the Rep proteins from the pMV158 family [46] (Figure 4D). Consistent with this finding, a double-strand origin (dso) typical of pMV158 family was identified upstream of $\operatorname{cop} G$ (Figure 4B). These $d s o$ shared a conserved cleavage site TACTAC(C) G/A between two inverted repeats. The other replication origin, the lagging-strand initiation site (sso), was also predicted upstream of the $d s o$ by analogy with results obtained for other mycoplasma plasmids [22,23] (data not shown). Therefore, replication of all mycoplasma plasmids is likely to be driven through a rollingcircle mechanism by a Rep protein of the pMV158 family type.

\section{Mosaic structure of the mycoplasma plasmids is indicative of recombination events}

In spite of a conserved structure, multiple pair-wise DNA sequence comparisons indicated that mycoplasma plasmids are in fact a mosaic of rep, dso, copG, and sso blocks. This was evidenced by the occurrence of several local regions of homology detected by using the BLAST program (Figure 5). Pairs of plasmids that show a high level of identity for the Rep sequence (e.g. pKMK1 and pMG1B-1; pMG2D-1 and pMG2B-1) do not necessarily share a high degree of identity for the region upstream of $\operatorname{cop} G$. Interestingly, high sequence identity for the region spanning sso was found to be indicative of plasmids being hosted by the same mycoplasma species. For instance, the following plasmid-pairs, pADB201 and pKMK1, pMG1B-1 and pMG2D-1, and pMG2B-1 and pMG2F-2 were isolated from $M m c, M c c$, and $M$. yeatsii, respectively (Figure 5). This result is consistent with the fact that during replication this region interacts with chromosome-encoded components [18]. Further degrees of mosaicism were found in particular cases such as for pMG2D-1, in which two putative dso showing sequence heterogeneity are found. Other examples of genetic variability are the small size of pBG7AU and the unusual location of the dso in pMG2F-2. Such a mosaic structure is clearly indicative of successive recombination events between replicons. 


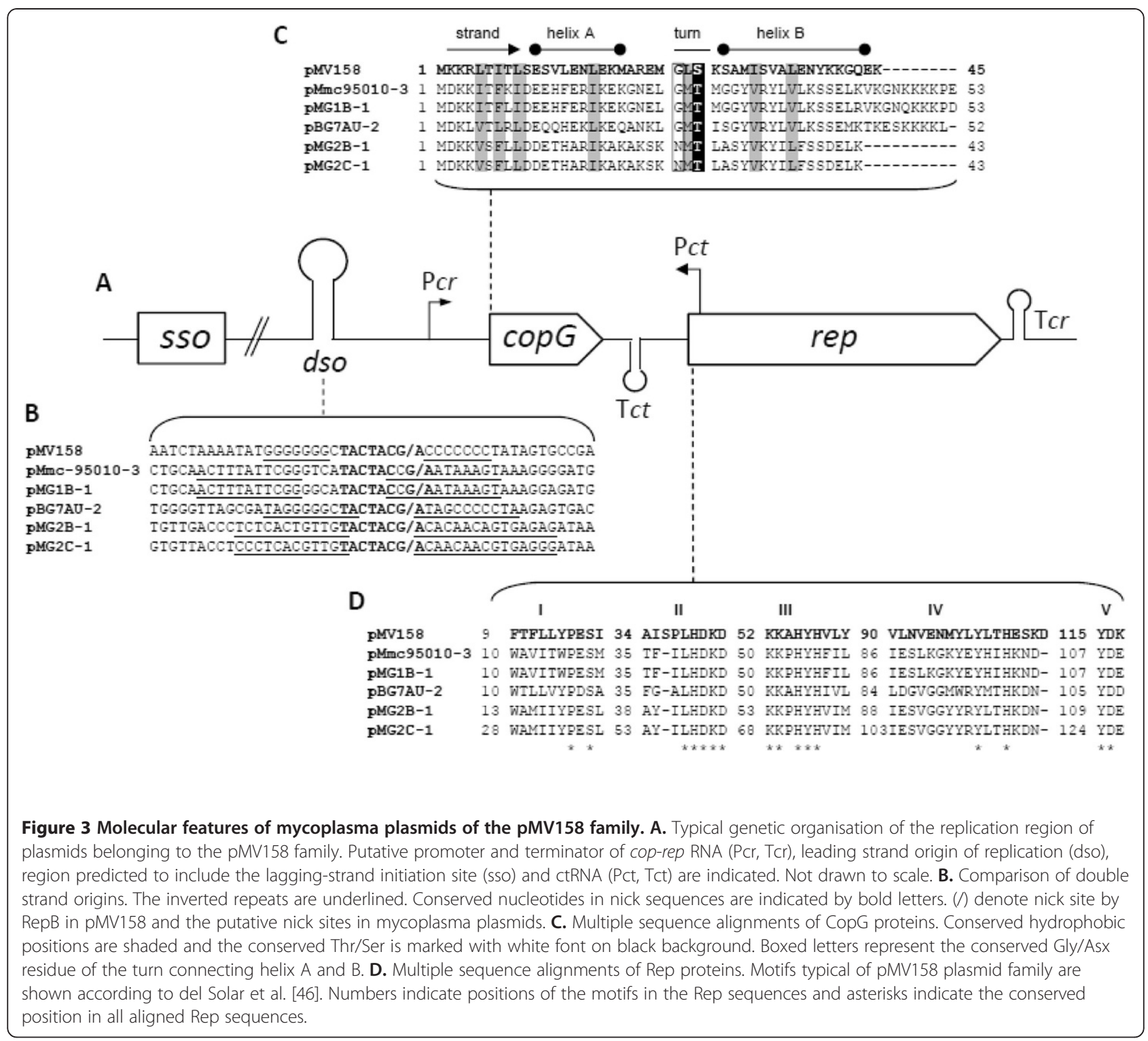

\section{pMyBK1 is a unique representative of a new replicon family}

As indicated above, $M$. yeatsii strain GIH TS was the only strain that yielded a banding pattern of extrachromosomal DNA that suggested the presence of two distinct plasmids (Figure 5A). The small plasmid, pMG2B-1, was shown to belong to the pMV158 family like all other mycoplasma plasmids (Figure 3). In contrast, the larger plasmid (3,432 bp) named pMyBK1 (GenBank Accession number EU429323; [25]) has a genetic organization that sets it apart from the other mycoplasma plasmids. Initial database searches using pMyBK1 sequence as a query indicated low identity with other plasmids and prompted us to further analyze this plasmid that might represent a new family of replicons.
First, the relative copy number of each plasmid of $M$. yeatsii $\mathrm{GIH}^{\mathrm{T}}$, pMG2B-1 and pMyBK1, was evaluated by two different methods (gel assay and real-time PCR). Both methods yielded similar results with estimated copy number of 154-170 copies/cell and of 56-60 copies/cell for pMyBK1 and pMG2B-1, respectively (Figure 5B). Such a difference strongly suggests that the two plasmids have distinct replication and /or regulation systems. Together the $2 \mathrm{M}$. yeatsii plasmids represent a total extrachromosomal DNA amount of $636 \mathrm{kbp}$ per cell, which is approximately $37 \%$ of the total cell DNA.

Next, the genetic structure of pMyBK1 was analyzed. The 2 CDSs found in the pMyBK1 sequence (CDSA and $\mathrm{B}$, encoding polypeptides of respectively 519 and 272 aa) showed no homolog with other mycoplasma plasmids (Figure 2A). The presence of a 192-bp intergenic region 


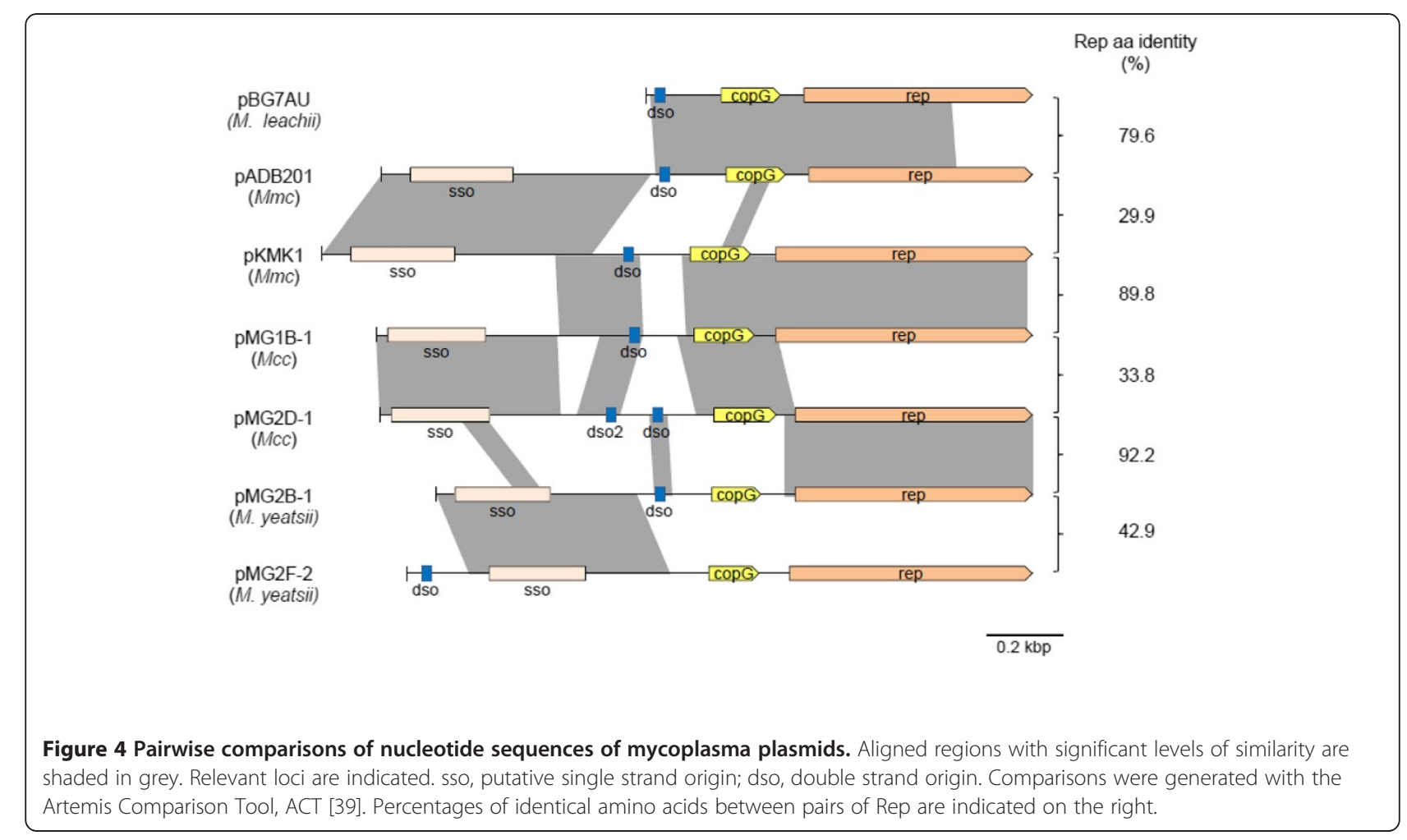

between the CDSs as well as the predicted rhoindependent transcription terminator immediately downstream of each CDS strongly suggests that the 2 CDSs are transcribed independently rather than as a single operon. The deduced amino acid sequence of pMyBK1 CDSA exhibits low but significant similarity with mobilization proteins of various bacteria. The N-terminal part of the CDSA protein contains a Mob/Pre domain (pfam01076) typical for relaxases of the MobV superfamily that includes proteins involved in conjugative mobilization and plasmid intramolecular recombination [49]. Sequence alignments with representatives of the MobV family clearly showed that the CDSA protein did possess the three conserved motifs of the family [50] (data not shown). Subsequent phylogenetic analyses of the CDSA polypeptide with the complete set of MobV proteins described by GarcillanBarcia [51] classified the pMyBK1 protein within the MobV4 relaxase family (data not shown).

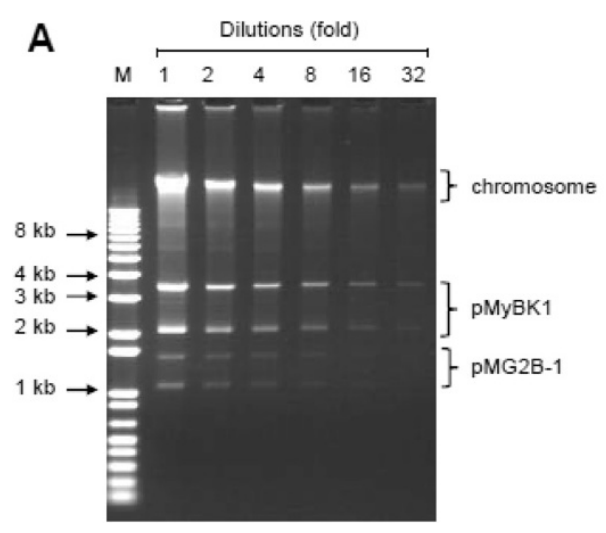

B

\begin{tabular}{lll}
\hline Method & \multicolumn{2}{c}{ Plasmid copy number } \\
\cline { 2 - 3 } & pMG2B-1 & pMyBK1 \\
\hline Gel assay & $60.2 \pm 6.2$ & $170.6 \pm 20.3$ \\
Real-time & $56.0 \pm 1.6$ & $154.4 \pm 14.3$ \\
PCR & & \\
\hline
\end{tabular}

Figure 5 Analysis of plasmid content of Mycoplasma yeatsii type strain GIH (TS). A. Agarose gel electrophoresis of total DNA. Lanes were loaded after twofold dilution series of the DNA preparation obtained as described in Methods. Bands corresponding to the chromosome and the 2 plasmids are identified. Lane M, DNA ladder. B. Estimated plasmid copy number of pMyBK1 and pMG2B-1 as estimated by gel assay (Panel A) and relative real-time PCR as described in Methods. 
In contrast to CDSA, no functional domain or characteristic secondary structure was identified in the CDSBencoded protein. Blast searches revealed that the CDSB protein of pMyBK1 shared significant homology with five chromosome-encoded proteins of $\mathrm{Mcc}$, strain California Kid, or M. leachii, strain PG50 and 99/014/6 but with no known associated function.

\section{Identification of the replication protein and the mode of replication of $\mathrm{pMyBK1}$}

Since none of the pMyBK1-encoded proteins share homology to known replication proteins, CDSA and CDSB were both regarded as putative candidates. To identify the replication protein and delineate the replication region of pMyBK1, a series of deletion and frameshift mutations were introduced in a shuttle plasmid (E. coli/ $M$. yeatsii), named $\mathrm{pCM}-\mathrm{H}$, that was constructed by combining $\mathrm{pMyBK} 1$ to a colE1 replicon carrying the tet $M$ tetracycline resistance gene as the selection marker (Figure 2A). The mutated plasmids were then introduced into a plasmid-free $M$. yeatsii strain (\#13156 from the Anses collection) by PEG-transformation, and their replication capacity was measured by the number of resulting tetracycline resistant colonies. Plasmids $\mathrm{pCM}-\mathrm{P}$ and $\mathrm{pCM}$ $\mathrm{K} 1$ contain respectively CDSA and CDSB, associated with the flanking intergenic regions (Figure 2A). No transformant was obtained with PCM-P, confirming that CDSA, which encodes a putative Mob protein (see before), is not the replication protein and that none of the intergenic regions is sufficient to sustain plasmid replication. In contrast, the replication of pCM-K1 in M. yeatsii was abolished after introducing a frameshift mutation that disrupts CDSB (pCM-K1 $\triangle \mathrm{B}$ in Figure 2A). This strongly argues for CDSB encoding the replication protein of pMyBK1, a result that confirms recent findings [25]. Successive reductions of the region downstream of CDSB, including the $\mathrm{GC}$ rich sequence located immediately upstream of CDSA of the native plasmid, led to a minimal replicon pCM-K4 of 1,297 bp (Figure 2A). In pCM-K4, the region downstream of CDSB is characterized by the presence of two sets of direct repeats. In addition, a 44-bp partially palindromic sequence with the potential to form a stable stem-loop structure $(\Delta G=-8.71 \mathrm{kcal} / \mathrm{mol})$ is located immediately downstream of the direct repeat region. Interestingly, this structure was found to be essential for plasmid replication as deletion of the stem-loop 5'arm in pCM-K5 totally abolished plasmid replication (Figure 3A).

Detection of single-stranded (ssDNA) intermediates, generated during replication, is the hallmark of plasmids replicating via a rolling-circle mechanism $[40,52]$. After treatment of some of the DNA samples with ssDNA-specific nuclease S1, total DNAs from M. yeatsii GIH TS were separated by agarose gel electrophoresis before being transferred to nylon membranes under non-denaturating conditions. Hybridization with the pMyBK1 probe could only be detected when S1nuclease treatment was omitted (Additional file 5: Figure S2). The hybridization signal was completely absent in the corresponding, S1-nuclease treated samples (Additional file 5: Figure S2). These results confirmed the existence of ssDNA intermediates and indicate that pMyBK1 probably replicates via the RCR mechanism. Since CDSB protein has no similarity with any known replication protein, $\mathrm{pMyBK} 1$ is therefore considered as the first member of a new RCR replicon family.

\section{Host specificity of pMyBK1}

The lack of significant similarity between the putative Rep of pMyBK1 and the Rep proteins from other mycoplasma plasmids confirms that pMyBK1 belongs to a previously unknown class of RCR plasmids. However, the fact that pMyBK1 is hosted by a mycoplasma species (M. yeatsii) sharing a common host (goat) and body site (ear canal) with other ruminant mycoplasmas [53,54] raises the question of the putative dissemination of this plasmid. Therefore, the ability of $\mathrm{pMyBK} 1$ derivatives to replicate in various mollicute species of the Mycoplasma and Spiroplasma genera was evaluated. Using the standard PEG-transformation protocol, the pMyBK1derivatives $\mathrm{pCM}-\mathrm{K} 3 / 4$ (Figure 2B) were successfully introduced into the following plasmid-free strains: $M$. yeatsii \#13156, M. putrefaciens KS1 TS, M. leachii PG50 TS and Mcc California kid TS. The autonomous replication of the PMyBK1 derivatives in these species was confirmed by plasmid purification and backtransformation of $E$. coli with the purified plasmids. Transformation of $M m c$ with $\mathrm{pCM}-\mathrm{K} 3 / 4$ also yielded many tetracycline resistant transformants, but no free plasmid could be detected despite the positive PCR amplification of CDSB. These results suggest an integration of the pMyBK1 derivative into the host chromosome of this species, as it has been previously described for oriC plasmids [55]. Attempts to transform $M$. mycoides subsp. mycoides or Spiroplasma citri with pCMK3 repeatedly failed. Interestingly, we also showed that pMyBK1 not only replicated in various mycoplasma species but was also able to express heterologous genes. The spiralin gene encoding the major surface protein of S. citri was inserted into the EcoRI site of pCM-K3 and the resulting plasmid pCM-K3-spi (Figure 2A) was successfully introduced into M. yeatsii GIH TS and Mcc California Kid. Expression of spiralin by the transformants was demonstrated by immunoblotting (Additional file 6: Figure S3 for $M c c$ transformants, data not shown for $M$. yeatsii transformants). These results confirm and extend recently published results [25] indicating that pMyBK1 derivatives can be used as expression vectors in mycoplasma species of veterinary importance. 


\section{General phylogeny of Rep sequences from mycoplasma plasmids}

Based on the availability of 25 Rep sequences of mycoplasma plasmids (Additional file 3: Table S3), it was possible to address how these sequences cluster in the phylogenetic tree constructed with a set of sequences including representatives of RCR plasmids from both $\mathrm{Mol}$ licutes and Firmicutes (Figure 6). A set of 62 amino acids sequence corresponding to the replication protein of 25 mycoplasma plasmids and of 37 representatives of the major RCR plasmid families, including those of the phytoplasma plasmids was selected for constructing the phylogenetic tree. Phylogenetic analyses confirmed that, except for pMyBK1, all mycoplasma plasmids could be grouped within the pMV158 family (Figure 6). This result is consistent with the prediction, in these Rep sequences, of a Rep2 domain typical of this plasmid family. Yet, mycoplasma plasmids do not form a single, coherent group in this family but instead cluster into two distinct branches designated as groups 1 and 2. Rep proteins from groups 1 and 2 share only limited similarities and, the most divergent members in these groups are more distant between each other than they are from the streptococcal pMV158. Group 1 consists of highly similar proteins (identity ranging from 88 to $100 \%$ ) and includes Rep proteins from $M m c$ and $M c c$ plasmids. Conversely, group 2 is more heterogeneous and includes Rep proteins from M. leachii, M. yeatsii, M. cottewii, $M m c$ and $M c c$ plasmids. Further phylogenetic analyses showed that group 2 could be split into two statisticallysupported subgroups (2A and $2 \mathrm{~B}$ ).

It is noteworthy that a large group of phytoplasma plasmids also clusters within the pMV158 family. Nevertheless, the Rep proteins of phytoplasma plasmids are more closely related to Rep of mobile elements from non-mollicute bacteria than to those of mycoplasma plasmids. In addition, the Rep of phytoplasma plasmids are characterized by a C-terminal part having a helicase domain, which is absent in the Rep of mycoplasma plasmids.

\section{Conclusions}

This study was performed in the context of (i) conflicting reports regarding the prevalence of plasmids in mycoplasma species [3,24] and of (ii) the quest for MGE that may have served as genetic vehicles resulting in the high level of HGT reported among ruminant mycoplasmas [58]. We found a rather high prevalence of plasmids in species belonging to the $M$. mycoides cluster and, in contrast, a lack of plasmids in the M. bovis-M. agalactiae group. Therefore, these plasmids are unlikely to contribute by themselves to a significant part of the reported HGT, and therefore the role of other MGE, including ICEs, remains to be evaluated.
The present study has considerably increased our knowledge about the genetic organization of mycoplasma plasmids adding 21 new sequences to a repertoire of only 5 in the databases. With the exception of the previously reported $\mathrm{pMyBK} 1$ replicon, all the mycoplasma plasmids belong to the pMV158 family. As these plasmids only encode two genes, one essential for replication initiation and the other for control of copy number, they do not carry any accessory gene that may confer a new phenotype to the recipient cell.

The alignment of rep plasmid sequences resulted in a tree that does not fit the 16S rDNA phylogeny of the host species. For instance, the Rep proteins of $M c c$ pMG1B-1 and pMG2A-1 fall into two distinct groups whereas those of $M c c$ pMG2A-1 and M. yeatsii pMG2B1 are almost identical (Figure 6, Table S3). Incongruence between plasmid and chromosomal gene phylogenies has often been reported in bacteria and interpreted as the result of lateral plasmid transfer between diverse species $[59,60]$. In addition, plasmid phylogeny has probably been blurred by recombination events that resulted in a mosaic structure (Figure 4). The occurrence of several mycoplasma species within the same host (i.e. small ruminants) might have facilitated horizontal plasmid transfer within this bacterial genus. The driving force for this extrachromosomal inheritance has yet to be further studied taking into account the apparent lack of beneficial traits by the recipient species. Mechanisms underlying the transfer of plasmids between strains of ruminant mycoplasmas have yet to be deciphered since, the mycoplasma pMV158-like plasmids, like a majority of plasmids should be considered as non mobilizable/ non self-transmissible according to the classification of Smilie et al. [61]. Their small size favors transfer mechanisms like transduction, natural transformation and cointegration in mobile elements.

The topology of the rep phylogenetic tree (Figure 6) is not consistent with the idea of a common plasmid ancestor that would have been vertically inherited in both phytoplasma and mycoplasma clades. Moreover, the clear-cut clustering of mycoplasma plasmids into separate branches supports the hypothesis of several, rather than a single, mycoplasma plasmid ancestors. Using the clustering of rep sequences, we propose a new nomenclature system that applies to all currently described mycoplasma and phytoplasma plasmids. This classification does not take into account the plasmid host as these elements are transmissible from one species to another. As the spiroplasma plasmids do not carry a rep sequence showing a significant homology with those described here (Figure 6), they cannot be included in this nomenclature.

While this paper was under review, Kent et al. published a study showing the use of $\mathrm{pMyBK} 1$ as a shuttle 


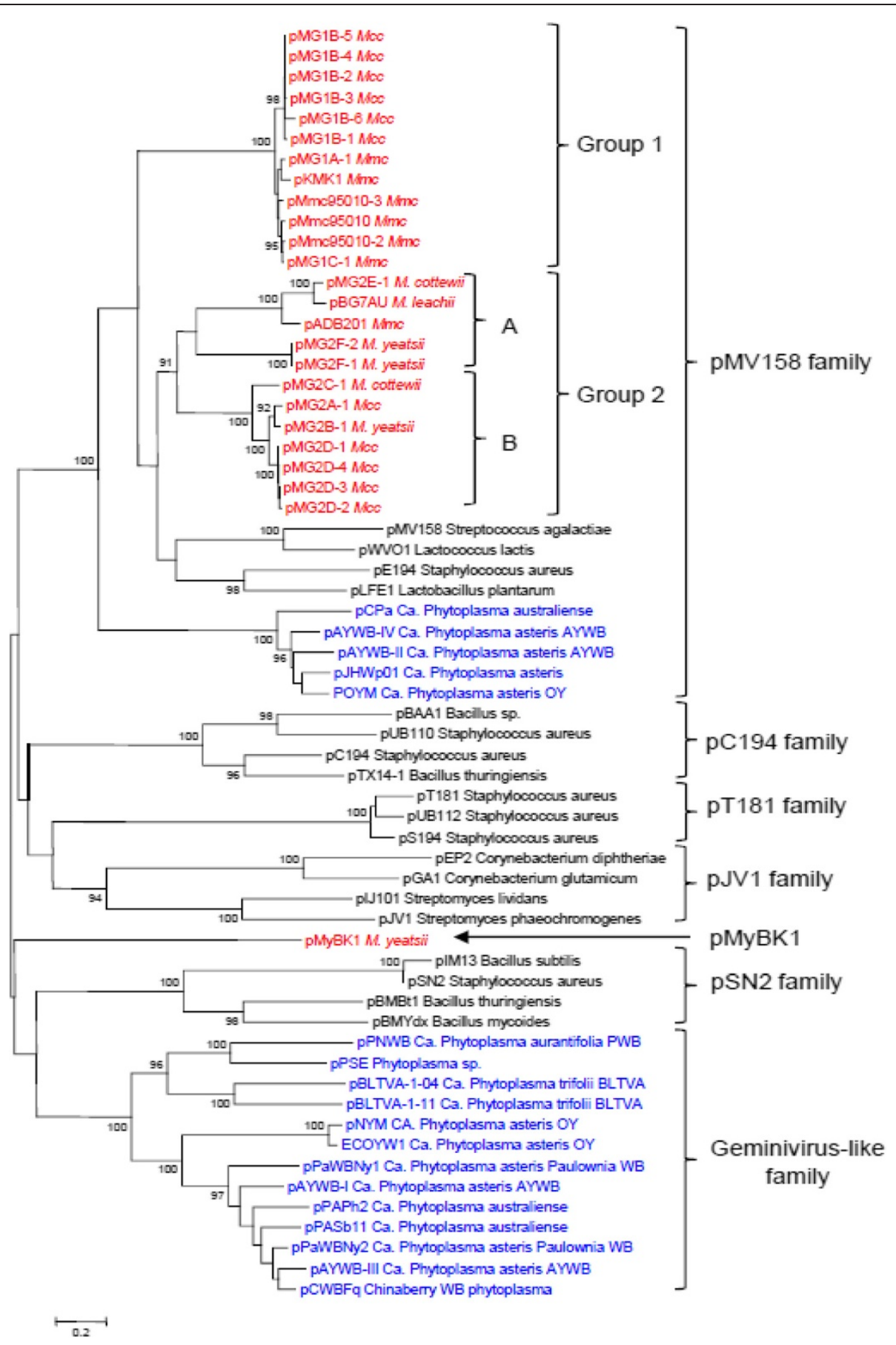

Figure 6 Phylogenetic relationships among RCR plasmids based on Rep protein sequences. The evolutionary history was inferred using the Neighbor-Joining method [56]. The percentage of replicate trees in which the associated sequences clustered together in the bootstrap test (1000 replicates) are shown next to the branches [57]. Plasmids from mollicutes are indicated in red (mycoplasmas) and blue (phytoplasmas).

vector for heterologous gene expression in $M$. yeatsii [25]. We confirm that pMyBK1 represents a novel RCR plasmid family and that its derivatives can be used as gene vectors to express cloned genes not only in $M$. yeatsii [25] but also in three other ruminant mycoplasmas. This result is not trivial in a group of organisms for which the genetic toolbox is very limited. The pMyBK1 plasmid has a small size, lacks any CDS homologous to 
genes for mating pair formation but encodes a relaxase belonging to the MobV class. These features argue for a mobilizable rather than conjugative nature of the plasmid $[25,62]$. The fact that pMyBK1 was only detected in $M$. yeatsii is inconsistent with the finding that it replicates in mycoplasma species other than $M$. yeatsii, at least when introduced experimentally. Two hypotheses would explain this apparent contradiction. One is that the transfer of pMyBK1 is a rare event and hence, the number of strains screened was not large enough to detect additional pMyBK1-related plasmids. The other is that pMyBK1 would not be transferred in vivo or would not be stably maintained once transferred.

\section{Additional files}

\section{Additional file 1: Table S1. Additional file 5 \\ Additional file 2: Table S2. History of mycoplasma strains and plasmid screening.}

Additional file 3: Table S3. Pairwise nucleic sequence identities between mycoplasma plasmids. Global alignments of the full-length nucleic sequence of mycoplasma plasmids were accomplished using a Needleman-Wunsch algorithm implemented in the Needleall program (Needleman \& Wunsch, 1970). Identity percents are indicated. Rep group refers to Rep phylogeny (see Figure 6). Table S3. Pairwise nucleic sequence identities between mycoplasma plasmids. Global alignments of the full-length nucleic sequence of mycoplasma plasmids were accomplished using a Needleman-Wunsch algorithm implemented in the Needleall program (Needleman \& Wunsch, J Mol Biol 1970;48:443-53). Identity percents are indicated. Rep group refers to Rep phylogeny (see Figure 6).

Additional file 4: Figure S1. Nucleotide sequences of the predicted ctRNA coding strands. The counter-transcripts were first identified by analogy with those of pMV158 or its derivative pLS1. These ctRNA overlap the rep gene start and have a length of only a few tens of nucleotides. Using the consensus sequence TTGACA - (N17) -TG-NTATAAT for the promoter, putative promoters were identified in the aligned sequences. Putative PCt promoters are indicated with the -35 and -10 regions in bold and underlined letters. Arrows indicate inverted repeats of the putative rho independent terminators. The ctRNA of pLS1 (rnall) is shown as proposed by del Solar et al. [46] with an arrowhead indicating the possible transcriptional initiation site. The box CAT indicates the initiation codon of the rep gene that is encoded on the complementary DNA strand.

Additional file 5: Figure S2. Detection of pMyBK1 ssDNA intermediates by Southern blot hybridization. Total DNA from Mycoplasma yeatsii type strain GIH TS (lane 1-2) was analyzed on a $0.8 \%$ agarose gel (A) with (+) or without (-) prior 51 nuclease treatment. Southern blot (B) was performed with digoxigenin-labeled pMyBK1 probe under nondenaturing conditions. $\mathbf{M}$, DNA ladder.

Additional file 6: Figure S3. Expression of spiralin in Mcc using pMyBK1 derivatives. Whole cell dot immunoblot of 12 Mcc transformants harboring the spiralin expression vector pCM-K3-spi (a) or the empty vector pCM-K3 (b). Mycoplasma cells were applied to a nitrocellulose membrane and probed with rabbit anti-spiralin antibodies and anti-rabbit lgG peroxidase conjugate.

\section{Abbreviations}

(HGT): Horizontal gene transfer; (MGE): Mobile genetic elements; (ICEs): Integrative and conjugative elements; $(M m c)$ : $M$. mycoides subsp. capri; (Mcc): M. capricolum subsp. capricolum; (CDS): Coding Sequence; (dso): Leading strand origin of replication; (sso): Lagging-strand initiation site; (RCR): Rolling-circle replication; (PEG): Polyethylene glycol.
Competing interests

All the authors declare no competing interests.

\section{Authors' contributions}

$M B, F T, V M$ and ED-F carried out most of the experiments. MB, FT, CC, ED-F and $A B$ participated in the design of the study. $M B$ and $F T$ drafted the manuscript, all authors made suggestions for improvement. All authors participated in the data analysis. FT, CC and AB coordinated the study. All authors read and approved the final manuscript.

\section{Acknowledgements}

This work was supported by grant ANR09MIE016 (MycXgene) from the French national funding research agency (ANR) to CC (PI), by INRA, Région Aquitaine and ENVT. We would like to thank Guillaume Bouyssou, Agnès Tricot and Céline Michard for technical help. We would also like to thank Laure Maigre who made the first observation of the extrachromosomal elements in Mcc and M. yeatsii strains, and Eilean Bertram for revising the manuscript.

\section{Author details}

'University Bordeaux, UMR 1332 Biologie du Fruit et Pathologie, 71 avenue Edouard Bourlaux, F-33140, Villenave d'Ornon, France. ${ }^{2}$ INRA, UMR 1332 Biologie du Fruit et Pathologie, 71, avenue Edouard Bourlaux, F-33140, Villenave d'Ornon, France. ${ }^{3}$ Anses, Laboratoire de Lyon, UMR Mycoplasmoses des Ruminants, 31 Avenue Tony Garnier, F-69364, Lyon cedex 07, France. ${ }^{4}$ INRA, UMR1225, Ecole Nationale Vétérinaire de Toulouse, 23 Chemin des Capelles, F-31076, Toulouse Cedex 3, France. ${ }^{5}$ Université de Toulouse, INP-ENVT, UMR1225, Ecole Nationale Vétérinaire de Toulouse, 23 Chemin des Capelles, F-31076, Toulouse Cedex 3, France. ${ }^{6}$ Centre INRA de Bordeaux Aquitaine, UMR 1332 Biologie du Fruit et Pathologie, 71, avenue Edouard Bourlaux, BP81, F-33140, Villenave d'Ornon, France.

Received: 8 August 2012 Accepted: 5 November 2012

Published: 12 November 2012

\section{References}

1. Smets BF, Barkay $\mathrm{T}$ : Horizontal gene transfer: perspectives at a crossroads of scientific disciplines. Nature Reviews 2005, 3(9):675-678.

2. Frost $L S$, Leplae $R$, Summers $A O$, Toussaint $A$ : Mobile genetic elements: the agents of open source evolution. Nature reviews 2005, 3(9):722-732.

3. Razin S, Yogev D, Naot Y: Molecular biology and pathogenicity of mycoplasmas. Microbiol Mol Biol Rev 1998, 62(4):1094-1156.

4. Sirand-Pugnet P, Citti C, Barre A, Blanchard A: Evolution of mollicutes: down a bumpy road with twists and turns. Res Microbiol 2007 158(10):754-766

5. Weisburg WG, Tully JG, Rose DL, Petzel JP, Oyaizu H, Young D, Mandelco L, Sechest J, Lawrence TG, Van Etten J, et al: A phylogenetic analysis of mycoplasmas: basis for their classification. J Bacteriol 1989, 171:6455-6467.

6. Glass Jl, Assad-Garcia N, Alperovich N, Yooseph S, Lewis MR, Maruf M, Hutchison CA 3rd, Smith HO, Venter JC: Essential genes of a minimal bacterium. Proc Natl Acad Sci U S A 2006, 103(2):425-430.

7. Vasconcelos AT, Ferreira HB, Bizarro CV, Bonatto SL, Carvalho MO, Pinto PM Almeida DF, Almeida LG, Almeida R, Alves-Filho L, et al: Swine and poultry pathogens: the complete genome sequences of two strains of Mycoplasma hyopneumoniae and a strain of Mycoplasma synoviae. J Bacteriol 2005, 187(16):5568-5577.

8. Pereyre $S$, Sirand-Pugnet $P$, Beven L, Charron A, Renaudin H, Barre A, Avenaud $P$, Jacob D, Couloux A, Barbe $V$, et al: Life on arginine for Mycoplasma hominis: clues from its minimal genome and comparison with other human urogenital mycoplasmas. PLoS Genetics 2009, 5(10):e1000677.

9. Tamura K, Nei M: Estimation of the number of nucleotide substitutions in the control region of mitochondrial DNA in humans and chimpanzees. Mol Biol Evol 1993, 10(3):512-526.

10. Tamura K, Peterson D, Peterson N, Stecher G, Nei M, Kumar S: MEGA5: molecular evolutionary genetics analysis using maximum likelihood, evolutionary distance, and maximum parsimony methods. Mol Biol Evol 2011, 28(10):2731-2739.

11. Mouches C, Bove JM: A plasmid from S. citri strain M14 hybridizes with extrachromosomal DNAs from other spiroplasmas, including corn stunt 
spiroplasma E275, tick spiroplasma 277F, and coco spiroplasma N525. Yale J Biol Med 1983, 56(5-6):723-727.

12. Ranhand JM, Mitchell WO, Popkin TJ, Cole RM: Covalently closed circular deoxyribonucleic acids in spiroplasmas. J Bacterio/ 1980, 143(3):1194-1199.

13. Gasparich GE, Hackett KJ, Clark EA, Renaudin J, Whitcomb RF: Occurrence of extrachromosomal deoxyribonucleic acids in spiroplasmas associated with plants, insects, and ticks. Plasmid 1993, 29(2):81-93.

14. Berho N, Duret S, Danet JL, Renaudin J: Plasmid pSci6 from Spiroplasma citri GIl-3 confers insect transmissibility to the non-transmissible strain $S$. citri 44. Microbiology (Reading, England) 2006, 152(Pt 9):2703-2716.

15. Breton M, Duret S, Danet JL, Dubrana MP, Renaudin J: Sequences essential for transmission of Spiroplasma citri by its leafhopper vector, Circulifer haematoceps, revealed by plasmid curing and replacement based on incompatibility. App/ Environ Microbiol 2010, 76(10):3198-3205.

16. Firrao G, Garcia-Chapa M, Marzachi C: Phytoplasmas: genetics, diagnosis and relationships with the plant and insect host. Front Biosci 2007, 12:1353-1375.

17. Khan SA: Plasmid rolling-circle replication: recent developments. $\mathrm{Mol}$ Microbiol 2000, 37(3):477-484

18. Khan SA: Plasmid rolling-circle replication: highlights of two decades of research. Plasmid 2005, 53(2):126-136.

19. Brown DR, May M, Bradbury JM, Balish MF, Calcutt MJ, Glass JI, Tasker S, Messick JB, Johansson KE, Neimark H: Genus I. Mycoplasma Nowak 1929, 1349 nom. cons. Jud. Comm. Opin. 22, 1958, 166AL. In Bergey's Manual of Systematic Bacteriology. Second Editionth edition. Edited by Krieg NR, Staley JT, Brown DR, Hedlund BP, Paster BJ, Ward NL, Ludwig W, Whitman WB. New York, N.Y.: Springer; 2011:575-613.

20. Bergemann AD, Whitley JC, Finch LR: Homology of mycoplasma plasmid pADB201 and staphylococcal plasmid pE194. J Bacteriol 1989, 171(1):593-595.

21. Djordjevic SP, Forbes WA, Forbes-Faulkner J, Kuhnert P, Hum S, Hornitzky MA, Vilei EM, Frey J: Genetic diversity among Mycoplasma species bovine group 7: Clonal isolates from an outbreak of mastitis, and abortion in dairy cattle. Electrophoresis 2001, 22(16):3551-3561.

22. King KW, Dybvig K: Nucleotide sequence of Mycoplasma mycoides subspecies mycoides plasmid pKMK1. Plasmid 1992, 28(1):86-91.

23. Thiaucourt F, Manso-Silvan L, Salah W, Barbe V, Vacherie B, Jacob D, Breton M, Dupuy $V$, Lomenech AM, Blanchard A, et al: Mycoplasma mycoides, from "mycoides Small Colony" to "capri". A microevolutionary perspective. BMC Genomics 2011, 12:114

24. Nascimento ER, DaMassa AJ, Yamamoto R, Nascimento MGF: Plasmids in Mycoplasma species isolated from goats and sheep and their preliminary typing. Rev Microbiol 1999, 30(1):32-36.

25. Kent BN, Foecking MF, Calcutt MJ: Development of a novel plasmid as a shuttle vector for heterologous gene expression in Mycoplasma yeatsii. J Microbiol Methods 2012, 91(1):121-127.

26. Chazel M, Tardy F, Le Grand D, Calavas D, Poumarat F: Mycoplasmoses of ruminants in France: recent data from the national surveillance network. BMC Vet Res 2010, 6(1):32

27. Tully JG: Molecular and diagnostic procedures in mycoplasmology. In Molecular and diagnostic procedures in mycoplasmology, Volume I. Edited by Razin S, J.G T. San Diego: Academic press, Inc; 1995:33-39.

28. Freundt EA: Culture media for classic mycoplasmas. In Methods in Mycoplasmology, Volume I. Edited by Razin S, Tully JG. New York: Academic Press; 1983:127-135.

29. Pushnova EA, Geier M, Y.S Z: An easy and accurate agarose gel assay for quantitation of bacterial plasmid copy numbers. Anal Biochem 2000 284:70-76.

30. Abramoff MD, Magalhaes PJ, Ram SJ: Image processing with ImageJ. Biophotonics International 2004, 11(7):36-42.

31. Lee C, Kim J, Shin SG, Hwang S: Absolute and relative QPCR quantification of plasmid copy number in Escherichia coli. J Biotechnol 2006, 123(3):273-280.

32. Bocs S, Cruveiller S, Vallenet D, Nuel G, Medigue C: AMIGene: Annotation of Mlcrobial Genes. Nucleic Acids Res 2003, 31(13):3723-3726.

33. Marchler-Bauer A, Lu S, Anderson JB, Chitsaz F, Derbyshire MK, DeWeeseScott C, Fong JH, Geer LY, Geer RC, Gonzales NR, et al: CDD: a Conserved Domain Database for the functional annotation of proteins. Nucleic Acids Res 2011, 39(Database issue):D225-D229.

34. Geourjon C, Deleage G: SOPM: a self-optimized method for protein secondary structure prediction. Protein Eng 1994, 7(2):157-164.
35. Betley JN, Frith MC, Graber JH, Choo S, Deshler JO: A ubiquitous and conserved signal for RNA localization in chordates. Curr Biol 2002, 12(20):1756-1761.

36. Zuker M: Mfold web server for nucleic acid folding and hybridization prediction. Nucleic Acids Res 2003, 31(13):3406-3415.

37. Notredame C: Computing multiple sequence/structure alignments with the T-coffee package. Curr Protoc Bioinformatics 2010, 3(3 8):1-25.

38. Larkin MA, Blackshields G, Brown NP, Chenna R, McGettigan PA, McWilliam H, Valentin F, Wallace IM, Wilm A, Lopez R, et al: Clustal W and Clustal X version 2.0. Bioinformatics 2007, 23(21):2947-2948.

39. Carver T, Berriman M, Tivey A, Patel C, Bohme U, Barrell BG, Parkhill J, Rajandream MA: Artemis and ACT: viewing, annotating and comparing sequences stored in a relational database. Bioinformatics 2008, 24(23):2672-2676.

40. te Riele H, Michel B, Ehrlich SD: Are single-stranded circles intermediates in plasmid DNA replication? EMBO J 1986, 5(3):631-637.

41. Duret S, Berho N, Danet JL, Garnier M, Renaudin J: Spiralin is not essential for helicity, motility, or pathogenicity but is required for efficient transmission of Spiroplasma citri by its leafhopper vector Circulifer haematoceps. Appl Environ Microbiol 2003, 69(10):6225-6234.

42. Lartigue C, Duret S, Garnier M, Renaudin J: New plasmid vectors for specific gene targeting in Spiroplasma citri. Plasmid 2002, 48(2):149-159.

43. Stamburski C, Renaudin J, Bove JM: First step toward a virus-derived vector for gene cloning and expression in spiroplasmas, organisms which read UGA as a tryptophan codon: synthesis of chloramphenicol acetyltransferase in Spiroplasma citri. J Bacteriol 1991, 173(7):2225-2230

44. King KW, Dybvig K: Plasmid transformation of Mycoplasma mycoides subspecies mycoides is promoted by high concentrations of polyethylene glycol. Plasmid 1991, 26(2):108-115.

45. Burdett $\mathrm{V}$ : Identification of tetracycline-resistant R-plasmids in Streptococcus agalactiae (group B). Antimicrob Agents Chemother 1980, 18(5):753-760

46. del Solar G, Kramer G, Ballester S, Espinosa M: Replication of the promiscuous plasmid pLS1: a region encompassing the minus origin of replication is associated with stable plasmid inheritance. Mol Gen Genet 1993, 241(1-2):97-105

47. del Solar G, Acebo P, Espinosa M: Replication control of plasmid pLS1: efficient regulation of plasmid copy number is exerted by the combined action of two plasmid components, CopG and RNA II. Mol Microbiol 1995, 18(5):913-924.

48. Moscoso M, del Solar $G$, Espinosa M: In vitro recognition of the replication origin of pLS1 and of plasmids of the pLS1 family by the RepB initiator protein. J Bacteriol 1995, 177(24):7041-7049.

49. Priebe SD, Lacks SA: Region of the streptococcal plasmid pMV158 required for conjugative mobilization. J Bacteriol 1989, 171(9):4778-4784

50. Francia MV, Varsaki A, Garcillan-Barcia MP, Latorre A, Drainas C, de la Cruz F: A classification scheme for mobilization regions of bacterial plasmids. FEMS Microbiol Rev 2004, 28(1):79-100.

51. Garcillan-Barcia MP, Francia MV, de la Cruz F: The diversity of conjugative relaxases and its application in plasmid classification. FEMS Microbiol Rev 2009, 33(3):657-687.

52. del Solar G, Giraldo R, Ruiz-Echevarria MJ, Espinosa M, Diaz-Orejas R: Replication and control of circular bacterial plasmids. Microbiol Mol Biol Rev 1998, 62(2):434-464.

53. DaMassa AJD, Tully JG, Rose DL, Pitcher D, Leach RH, Cottew GS: Mycoplasma auris sp. nov., Mycoplasma cottewii sp. nov., and Mycoplasma yeatsii sp. nov., new sterol-requiring mollicutes from the external ear canals of goats. Int J Syst Bacteriol 1994, 44(3):479-484.

54. Jimena ON, Laura JM, Elena MM, Alonso NH, Teresa QM: Association of Raillietia caprae with the presence of Mycoplasmas in the external ear canal of goats. Prev Vet Med 2009, 92(1-2):150-153.

55. Lartigue C, Blanchard A, Renaudin J, Thiaucourt F, Sirand-Pugnet P: Host specificity of mollicutes oriC plasmids: functional analysis of replication origin. Nucleic Acids Res 2003, 31(22):6610-6618.

56. Saitou N, Nei M: The neighbor-joining method: a new method for reconstructing phylogenetic trees. Mol Biol Evol 1987, 4(4):406-425.

57. Felsenstein J: Phylogenies from molecular sequences: inference and reliability. Annu Rev Genet 1988, 22:521-565.

58. Sirand-Pugnet $P$, Lartigue $C$, Marenda $M$, Jacob D, Barré $A$, Barbe $V$, Schenowitz C, Mangenot S, Couloux A, Segurens B, et al: Being pathogenic, 
plastic, and sexual while living with a nearly minimal bacterial genome. PLoS Genet 2007, 3(5):e75.

59. Davies J, Smith DI: Plasmid-determined resistance to antimicrobial agents. Annu Rev Microbiol 1978, 32:469-518.

60. Valdes AM, Pinero D: Phylogenetic estimation of plasmid exchange in bacteria. Evolution 1992, 46(3):641-656.

61. Smillie C, Garcillan-Barcia MP, Francia MV, Rocha EP, de la Cruz F: Mobility of plasmids. Microbiol Mol Biol Rev 2010, 74(3):434-452

62. de Antonio C, Farias ME, de Lacoba MG, Espinosa M: Features of the plasmid pMV158-encoded MobM, a protein involved in its mobilization. J Mol Biol 2004, 335(3):733-743.

doi:10.1186/1471-2180-12-257

Cite this article as: Breton et al:: Distribution and diversity of

mycoplasma plasmids: lessons from cryptic genetic elements. BMC

Microbiology 2012 12:257.

\section{Submit your next manuscript to BioMed Central and take full advantage of:}

- Convenient online submission

- Thorough peer review

- No space constraints or color figure charges

- Immediate publication on acceptance

- Inclusion in PubMed, CAS, Scopus and Google Scholar

- Research which is freely available for redistribution 